\title{
Endoscopic transorbital surgery for Meckel's cave and middle cranial fossa tumors: surgical technique and early results
}

\author{
${ }^{*}$ Chiman Jeon, MD, ${ }^{1}$ Chang-Ki Hong, MD, PhD, ${ }^{2}$ Kyung In Woo, MD, PhD, ${ }^{3}$ \\ Sang Duk Hong, MD, MS, ${ }^{4}$ Do-Hyun Nam, MD, PhD, ${ }^{1}$ Jung-II Lee, MD, PhD, ${ }^{1}$ \\ Jung Won Choi, MD, PhD, ${ }^{1}$ Ho Jun Seol, MD, PhD, ${ }^{1}$ and Doo-Sik Kong, MD, PhD1
}

\begin{abstract}
Departments of ${ }^{1}$ Neurosurgery, ${ }^{3}$ Ophthalmology, and ${ }^{4}$ Otorhinolaryngology-Head and Neck Surgery, Samsung Medical Center, Sungkyunkwan University School of Medicine; and 'Department of Neurosurgery, Gangnam Severance Hospital, Yonsei University, Seoul, Republic of Korea
\end{abstract}

\begin{abstract}
OBJECTIVE Tumors involving Meckel's cave remain extremely challenging because of the surrounding complex neurovascular structures and deep-seated location. The authors investigated a new minimal-access technique using the endoscopic transorbital approach (eTOA) through the superior eyelid crease to Meckel's cave and middle cranial fossa lesions and reviewed the most useful surgical procedures and pitfalls of this approach.

METHODS Between September 2016 and January 2018, the authors performed eTOA in 9 patients with tumors involving Meckel's cave and the middle cranial fossa. The lesions included trigeminal schwannoma in 4 patients, meningioma in 2 patients, metastatic brain tumor in 1 patient, chondrosarcoma in 1 patient, and dermoid cyst in 1 patient. In 7 of the 9 patients, eTOA alone was performed, while the other 2 patients underwent a combined eTOA and endoscopic endonasal approach or retrosigmoid craniotomy. Data including details of surgical techniques and clinical outcomes were recorded. RESULTS Gross-total resection was performed in 7 of the 9 patients (77.8\%). Four patients underwent extended eTOA (with lateral orbital rim osteotomy). Drilling of the trapezoid sphenoid floor, a middle fossa "peeling" technique, and full visualization of Meckel's cave were applied to approach the lesions. Tumors were exposed and removed extradurally in 3 patients and intradurally in 6 patients. There was no postoperative CSF leak.
\end{abstract}

CONCLUSIONS The eTOA affords a direct route to access Meckel's cave and middle cranial fossa lesions. With experience, this novel approach can be successfully applied to selected skull base lesions. To achieve successful removal of the tumor, emphasis should be placed on the importance of adequately removing the greater sphenoid wing and vertical crest. However, because of limited working space eTOA may not be an ideal approach for posterior fossa lesions.

https://thejns.org/doi/abs/10.3171/2018.6.JNS181099

KEYWORDS endoscopic transorbital approach; Meckel's cave; middle cranial fossa; cavernous sinus; oncology; surgical technique

$\mathrm{S}$ KULL base lesions involving Meckel's cave and the middle cranial fossa remain surgically challenging because of the anatomical complexity of this area; the proximity to critical neurovascular structures, including several cranial nerves and the internal carotid artery (ICA); and the risk of profuse bleeding from the venous plexus. $21,22,31,36,44$ Classic transcranial approaches to such deep regions require extensive removal of bone and muscles and moderate brain retraction. 3,20,21,23,31,32,39 Although each approach has its own benefits and limitations, all methods commonly require brain retraction to some extent and even warrant extensive bone removal, including removal of zygomatic bone and the squamous part of the temporal bone for wide exposure. ${ }^{19,24,25,35,42}$ To date, outABBREVIATIONS ETOA = endoscopic transorbital approach; GTR = gross-total resection; ICA = internal carotid artery; IOF = inferior orbital fissure; MOB = meningo-orbital
band; PTR = partial tumor resection; SOF = superior orbital fissure; STR = subtotal resection.

SUBMITTED April 23, 2018. ACCEPTED June 27, 2018.

INCLUDE WHEN CITING Published online November 30, 2018; DOI: 10.3171/2018.6.JNS181099.

${ }^{*}$ C.J. and C.K.H. contributed equally to this work. 
standing achievements by many pioneering surgeons have enabled safe removal with acceptable morbidities.

In the era of neuroendoscopic surgery, an endoscopic transorbital approach (eTOA) through the superior eyelid crease has been proposed as a viable way to access anterior and middle cranial fossa lesions such as spheno-orbital meningioma. $3,5,13,22,26,28,41,43$ In addition to the visualization of cranio-orbital tumors, a surgical corridor through this approach allows excellent visualization of the lateral cavernous sinus while avoiding the need for brain retraction. ${ }^{9-13,15,26,28,34,35}$ Recent cadaveric studies have suggested that this approach allows direct access to Meckel's cave without disruption of the temporalis muscle, and craniotomy and has been emerging as a complementary route for accessing Meckel's cave.11,14,15,17,34 This novel surgical technique could facilitate minimally invasive surgery for skull base tumors. Given the relatively rare occurrence of tumors in Meckel's cave, the clinical efficacy of the exposure provided in these routes is still insufficient to clarify the selection of indications and methods. To our knowledge, this report is the first documentation of the use of this eTOA in a clinical series to provide endoscopic minimal access to middle fossa tumors using the transorbital route. Here, we share our preliminary experiences of a series of 9 patients who underwent endoscopic transorbital surgery for the aforementioned lesions and our evaluation of the feasibility of the new role of this approach in endoscopic skull base surgery.

\section{Methods}

We performed a retrospective interventional case series on all patients with a tumor involving Meckel's cave or the middle cranial fossa who had an eTOA via the superior eyelid crease incision under the guidance of neuronavigation. Spheno-orbital meningiomas invading the orbital wall were excluded from this study. All surgeries were performed between January 2016 and January 2018 by an eTOA team composed of a neurosurgeon (D.S.K.) and an oculoplastic surgeon (K.I.W.) in a single tertiary institution (Samsung Medical Center, Seoul, Korea), except 1 case for which surgery was performed by a single neurosurgeon (C.K.H.) at another independent tertiary institution (Gangnam Severance Hospital, Seoul, Korea). During this period, 9 patients underwent eTOAs for skull base lesions involving Meckel's cave and the middle cranial fossa. The mean patient age at the time of diagnosis was 55.2 years (range 38-64 years). There were 3 male and 6 female patients. Eight patients presented with newly diagnosed primary tumors, and 1 patient had a previous history of proton therapy for a lesion. None of the patients had undergone previous treatment via transcranial or endoscopic approaches. Clinical manifestations included dizziness $(n=2)$, headache $(n=1)$, progressive proptosis $(n=1)$, facial numbness $(n=2)$, seizure $(n=1)$, visual disturbance $(n=1)$, and vomiting $(n=1)$. Medical records were retrospectively reviewed and analyzed for presenting symptoms, surgical details, complications, follow-up, and postoperative functional outcomes. All patients underwent T1/T2-weighted and gadolinium-enhanced T1weighted MR imaging and follow-up postoperative MR imaging. Patients also had pre- and postoperative orbit CT scans to evaluate the extent of endoscopic orbital craniotomy. Gross-total resection (GTR) was defined as $100 \%$ tumor removal in the operation record and no remaining tumor lesion on postoperative MR imaging according to an independent radiologist. Subtotal resection (STR) was defined as greater than $90 \%$ tumor removal in the operation record or visible lesion remaining on postoperative MR imaging. Partial tumor resection (PTR) was defined as less than $90 \%$ tumor removal.

An ophthalmological evaluation including visual acuity, visual field, and limitation of ocular motility was obtained for all patients preoperatively and postoperatively. The study was approved by the hospital's Institutional Review Board (IRB) and adhered to the tenets of the Declaration of Helsinki. Main outcome measures were the extent of resection and postoperative complications. Data from some patients in this series were used for analysis of other aspects of this case series in additional studies by the authors.

\section{Results}

From January 2016 to January 2018, 9 patients underwent endoscopic transorbital resections for skull base lesions involving Meckel's cave and the middle cranial fossa. Among these patients, 1 patient had an eTOA combined with endoscopic endonasal surgery for removal of the clival tumor, and another patient underwent subsequent retrosigmoid suboccipital craniotomy for a remaining posterior fossa lesion. The tumors mainly involved Meckel's cave in 6 patients, and the tumors were located in the temporal lobe in 3 patients.

\section{Surgical Techniques \\ Eyelid Phase}

After induction of general anesthesia with endotracheal intubation, the patient was placed in a supine position with the head in a neutral or slight flexion position. Having the head in a flexion position affords easy surgical access to the floor of the temporal lobe. As previously described in the literature, ${ }^{9-12}$ an endoscope-assisted transorbital approach via the superior eyelid was performed under the guidance of an MRI- and CT-based neuronavigation system (Stealth, Medtronic). After placement of a lubricated corneal protector, a superior eyelid crease incision extending toward the lateral canthus was made by the oculoplastic surgeon (K.I.W.) or neurosurgeons (D.S.K. and C.K.H.). The superolateral border of the bony orbital rim was exposed after the orbicularis muscle was raised, with care being taken not to encroach upon the levator muscle and aponeurosis. The periosteum was then cut and, with a handheld rigid $0^{\circ}$ endoscope (Karl Storz), a subperiosteal dissection was performed from the lateral to inferomedial side until the margins of the superior orbital fissure (SOF) in the posterior wall of the orbit were identified.

\section{Orbital Phase}

Once periosteal dissection along the superolateral orbital wall exposed the lateral margin of the SOF, highspeed drilling using a 2- to 3-mm coarse diamond burr 

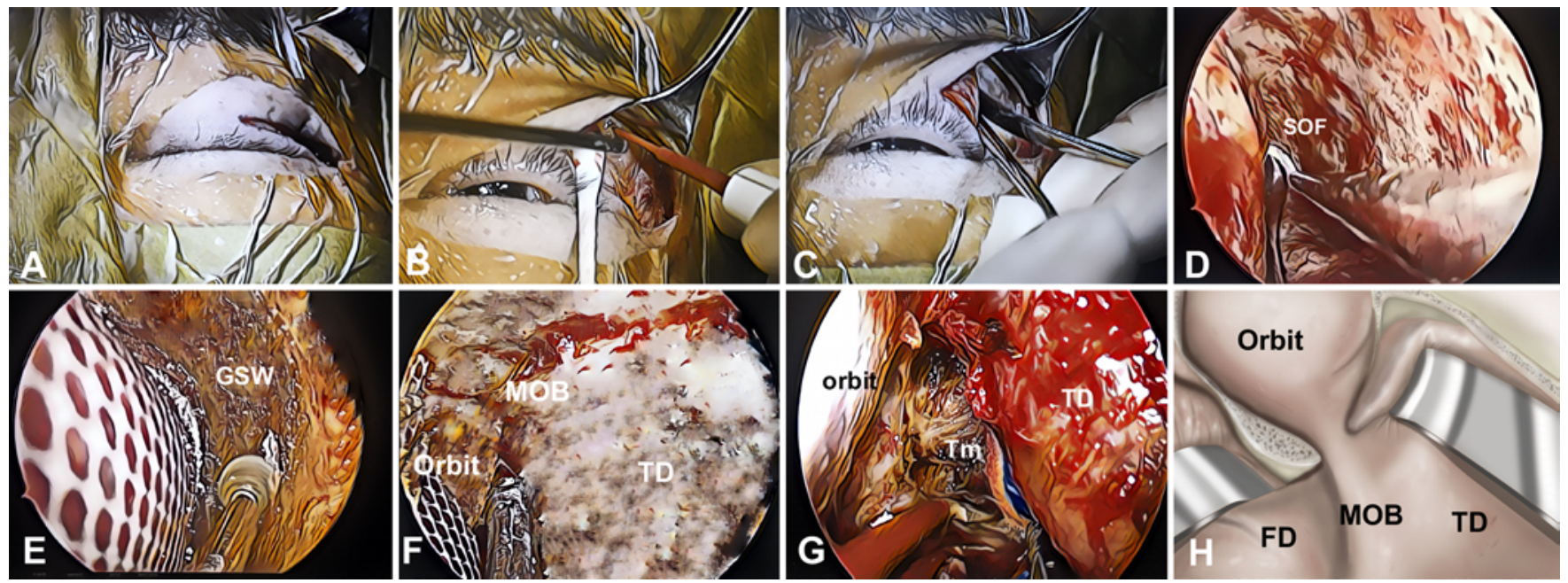

FIG. 1. Artistic illustration of each step in the endoscopic transorbital surgery. Superior eyelid incision (A). Periosteal incision on the superolateral orbital rim after subocularis dissection (B). Periosteal and periorbital elevation (C). Exposure of the SOF (D). Bone drilling on the greater sphenoid wing (GSW) while the orbit is covered with a silastic sheet (E). Exposure of the MOB between the orbit and the temporal dura (TD) (F). Exposure of tumor (Tm) between the TD and orbit after interdural dissection (G). Comparative illustration of the MOB as viewed in the transcranial approach $(\mathrm{H})$. FD = frontal dura. Copyright Doo-Sik Kong. Used with permission.

was performed from the lateral to the medial side, protecting the periorbita with a silastic sheet and a malleable rigid retractor. Minimal retraction force was applied with slight displacement of the orbital contents inferomedially while performing dissection and drilling. Because longstanding orbital retraction may often cause elevation of orbital pressure, resulting in cardiac arrhythmias, frequent monitoring of pupil size and blood pressure, along with electrocardiography, were required, and intermittent release from retraction of the eyeball was recommended. If necessary, additional osteotomy of the lateral orbital rim using chiseling, a so-called extended eTOA, was helpful to avoid excessive retraction of the globe and gain enough working space. Once the triangular-shaped bone of the greater wing of the sphenoid bone was drilled and the temporal dura began to be exposed, the rigid retractor was removed, and natural retraction with the instruments was intermittently used, resulting in minimal retraction force. The recurrent meningeal artery or meningolacrimal branch passing through the cranio-orbital foramen was usually encountered and easily interrupted with monopolar cauterization before the SOF was reached. The greater sphenoid wing was then carefully removed using a high-speed drill and 2-mm Kerrison rongeurs until the dura mater of the middle cranial fossa was fully exposed. Lateral to the inferior orbital fissure (IOF), the medial part of the greater sphenoid wing was drilled with a diamond burr to avoid injuries to critical neurovascular structures traversing the SOF. It was essential to achieve adequate removal of the lateral orbital wall and vertical crest of bone composing the IOF to obtain enough working space to enter the middle cranial fossa. Thus, complete bone drilling was performed until the superolateral margin of the IOF and the lateral margin of the SOF were fully exposed. As a result, an adequate working corridor was secured to avoid clashing (so-called sword fighting) of the endoscope and the surgical instruments. After the dura mater was fully exposed, no further retraction using a malleable retractor or spatula was required.

\section{Intracranial Phase}

For large-sized tumors involving the temporal lobe as well as the cavernous sinus, incision of the anterior dura of the temporal lobe was performed, allowing direct access to the tumor. The anterior-to-posterior path through the eTOA could obviate the necessity for retraction of the lateral temporal lobe. If necessary, the anterior temporal pole could be removed to access the lesion. Microsurgical technique was used throughout tumor removal. The tumor was first debulked with a suction or ultrasonic aspirator, followed by extracapsular sharp dissection. After adequate tumor removal, enough working space was gained to allow visualization of Meckel's cave medially and the normal adjacent temporal lobe laterally. For other lesions limited to Meckel's cave, an interdural dissection plane was obtained. At this phase, the first landmark was the meningo-orbital band (MOB) (also termed the frontoorbital-temporal polar dura), tethering the frontotemporal basal dura to the periorbita, which allowed entrance into the interdural space in the lateral wall of the cavernous sinus without interrupting the intradural space (Fig. 1). A slight incision at the MOB and a peel-off technique were used to gently dissect the interdural layers between the outer membrane of the cavernous sinus and the dura propria. The intersection of the dura allows entry to the cavernous sinus with direct visualization of the V1 and V2 space. Such an approach, through the anteromedial triangle, enabled a Hakuba approach along the lateral border of the outer membrane of the cavernous sinus in an anteroposterior direction. If necessary, even profuse bleeding from the cavernous sinus could be easily controlled with a Floseal or Gelfoam soaked with thrombin. To ap- 
TABLE 1. Patient characteristics and clinical outcomes of endoscopic transorbital surgery

\begin{tabular}{|c|c|c|c|c|c|c|c|c|c|c|c|}
\hline $\begin{array}{l}\text { Pt } \\
\text { No. }\end{array}$ & Sex & $\begin{array}{l}\text { Age } \\
\text { (yrs) }\end{array}$ & Diagnosis & $\begin{array}{c}\text { Meckel's } \\
\text { Cave } \\
\text { Involvement }\end{array}$ & $\begin{array}{c}\text { Ext } \\
\text { to Pst } \\
\text { Fossa }\end{array}$ & $\begin{array}{l}\text { Mid Cranial } \\
\text { Fossa } \\
\text { Involvement }\end{array}$ & $\begin{array}{l}\text { Surgical } \\
\text { Approach }\end{array}$ & $\begin{array}{c}\text { Intradural vs } \\
\text { Extradural } \\
\text { Work* }^{*}\end{array}$ & $\begin{array}{l}\text { Extent of } \\
\text { Resection }\end{array}$ & $\begin{array}{l}\text { Previous } \\
\text { Tx }\end{array}$ & $\begin{array}{l}\text { Procedure-Related } \\
\text { Complication }\end{array}$ \\
\hline 1 & M & 54 & Chondrosarcoma & Yes & No & Yes & eTOA+EEA & Intradural & GTR & None & \\
\hline 2 & $\mathrm{~F}$ & 66 & $\begin{array}{l}\text { Trigeminal } \\
\text { schwannoma }\end{array}$ & Yes & No & No & $\begin{array}{c}\text { Extended } \\
\text { eTOA }\end{array}$ & Extradural & GTR & None & $\begin{array}{l}\text { Complete ptosis, im- } \\
\text { proved in } 6 \text { mos }\end{array}$ \\
\hline 3 & M & 54 & $\begin{array}{l}\text { Metastatic brain } \\
\text { tumor }\end{array}$ & No & No & Yes & eTOA & Intradural & GTR & None & \\
\hline 4 & $\mathrm{~F}$ & 64 & $\begin{array}{l}\text { Trigeminal } \\
\text { schwannoma }\end{array}$ & Yes & No & Yes & eTOA & Extradural & GTR & None & \\
\hline 5 & M & 52 & $\begin{array}{l}\text { Trigeminal } \\
\text { schwannoma }\end{array}$ & Yes & Yes & Yes & $\begin{array}{l}\text { eTOA followed } \\
\text { by SOC }\end{array}$ & Intradural & $\begin{array}{l}\text { Intended } \\
\text { PTR }\end{array}$ & $\begin{array}{c}\text { Proton beam } \\
\text { therapy }\end{array}$ & \\
\hline 6 & $\mathrm{~F}$ & 60 & Dermoid cyst & Yes & Yes & No & eTOA & Extradural & GTR & None & \\
\hline 7 & $\mathrm{~F}$ & 56 & $\begin{array}{l}\text { Trigeminal } \\
\text { schwannoma }\end{array}$ & Yes & Yes & Yes & $\begin{array}{c}\text { Extended } \\
\text { eTOA }\end{array}$ & Intradural & GTR & None & \\
\hline 8 & $\mathrm{~F}$ & 53 & Meningioma & No & No & Yes & $\begin{array}{c}\text { Extended } \\
\text { eTOA }\end{array}$ & Intradural & GTR & None & \\
\hline 9 & $\mathrm{~F}$ & 38 & Meningioma & Yes & No & Yes & $\begin{array}{c}\text { Extended } \\
\text { eTOA }\end{array}$ & Intradural & STR & None & \\
\hline
\end{tabular}

EEA = endoscopic endonasal approach; ext = extension; mid = middle; $p s t$ = posterior; pt = patient; SOC = suboccipital craniotomy; Tx = treatment.

* Intradural work refers to surgery requiring a wide opening of the dura; extradural work refers to surgery without opening the dura.

proach the space between V2 and V3, extended eTOA might be more appropriate. The tumor was removed by applying the same technique as for the conventional transcranial approach. ${ }^{1,2,18,20}$ Obtaining an adequate working corridor allows free movement and manipulation of the instruments and endoscope. After removal of the tumor, trigeminal nerve rootlets could be identified medially or laterally, depending on the location of the tumor.

\section{Reconstruction Phase}

After complete removal of the tumors, hemostasis was achieved with bipolar forceps and Floseal, and the interdural space was filled with TachoSil. For reconstruction of the dural defect, we used a double-button technique (inlay and on-lay patch) using autologous fascia ${ }^{27}$ or acellular allogenic dermis (AlloDerm). To prevent postoperative enophthalmos (sunken eyeball), a wedge-shaped piece of polymerized absorbable Medpor was placed over the dural defect as a buttress. When the lateral orbital rim was removed in extended TOA, the orbital rim was reattached using a mini plate. Finally, the periosteum was sutured with 5-0 absorbable suture, and the skin was closed with 6-0 fast-absorbing plain gut. No routine drainage of CSF was required postoperatively.

\section{Clinical Outcomes}

Minimally invasive eTOA was achieved in 9 patients. On the preoperative MR imaging, lesions involved in Meckel's cave were confirmed in 7 patients. Three patients had tumors involving extension of the tumor from the middle to the posterior cranial fossa, which resulted in a dumbbell-shaped tumor in case 5 (Table 1). One patient had a tumor involving multiple compartments, including Meckel's cave, the middle cranial fossa, and the clivus. In another patient, a tumor extended into the infratemporal fossa through the foramen ovale. In 2 patients, the tumors were confined to the temporal lobe. An intraorbital extension of tumor in addition to Meckel's cave involvement was observed in 1 patient (Fig. 2 and Video 1).

VIDEO 1. Summary of the operation in case 2. Copyright Doo-Sik

Kong. Published with permission. Click here to view.

The final histopathological reports confirmed 4 trigeminal schwannomas (Fig. 3 and Video 2), 1 chondrosarcoma, 1 brain metastasis from renal cell carcinoma, 2 meningiomas, and 1 dermoid cyst (Fig. 4 and Video 2).

VIDEO 2. Summary of operations in cases 4,5 , and 6 . Copyright

Doo-Sik Kong. Published with permission. Click here to view.

Gross-total resection was achieved in 7 of the 9 patients (77.8\%). In 1 of 2 patients receiving PTR or STR, an intended PTR using eTOA was first performed for middle cranial fossa lesions and an additional retrosigmoid approach was performed for the remaining posterior fossa tumor. In the other patient, the tumor extending into the infratemporal fossa was left after removal of the intracranial portion. In the present series, there was no CSF leak after surgery. With regard to postoperative ptosis, 1 patient with trigeminal schwannoma showed a complete form of ptosis, and 3 patients had a mild form. All of the ptosis, including the complete form, was improved within 1 week to 6 months. No new visual impairment, diplopia, or other cranial palsy was observed, and no headaches were reported postoperatively. Detailed MR images for these cases are shown in Figs. 5 and 6.

\section{Discussion}

Skull base lesions involving Meckel's cave and the middle cranial fossa are surgically challenging because of the 

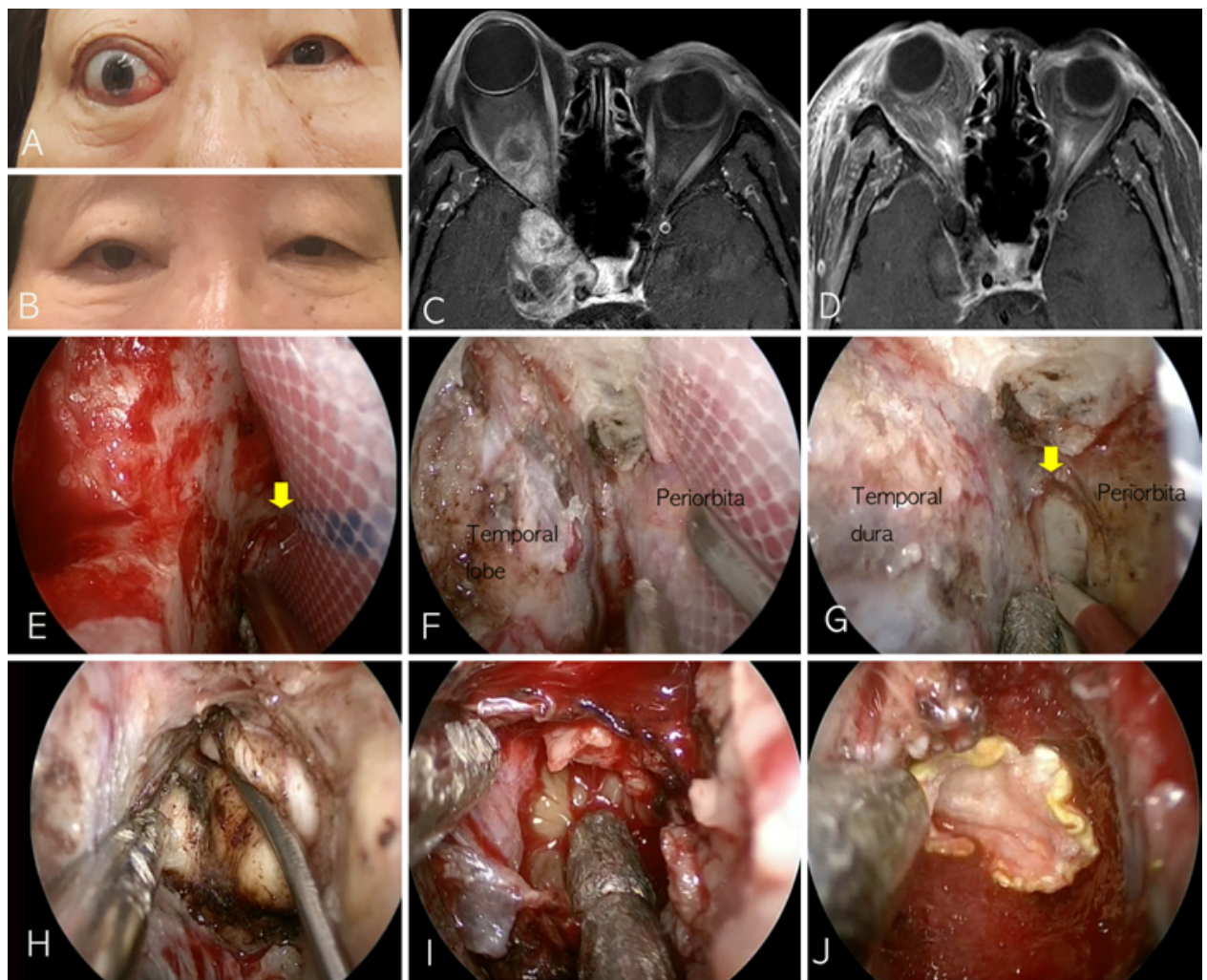

FIG. 2. Illustrative case 2. A 66-year-old woman with trigeminal schwannoma involving the lateral orbit and Meckel's cave presented with progressive proptosis of $18 \mathrm{~mm}(\mathbf{A})$. After endoscopic transorbital surgery, the patient had third nerve palsy and complete ptosis. However, the third nerve palsy was resolved 6 months after surgery (B). Preoperative MR imaging indicated that the tumor involved the cavernous sinus and extended into the orbit, resulting in severe proptosis (C). Postoperative MR imaging shows the area after GTR (D). Surgical details are as follows: after a skin incision along the superior eyelid crease, the periosteum was exposed over the lateral orbital rim, and lateral orbital osteotomy was performed. The periorbita was then elevated posteriorly up to the outer margin of the superior orbital fissure (arrow, E). Drilling with a high-speed diamond burr was performed with covering of the periorbita with a silastic sheet $(\mathbf{F})$. After full exposure of the temporal dura, the MOB (arrow) was cut and interdural dissection exposed the tumor capsule $(\mathbf{G})$. Tumor capsules were separately dissected from the surrounding tissues $(\mathbf{H})$. The tumor was first debulked (I) and then totally removed. The opening of the posterior fossa was sealed with TachoSil (J).

anatomical complexity and the proximity to critical neurovascular structures, including cranial nerves, the ICA, and the cavernous sinus. ${ }^{2,21,22,31,37,44}$ Traditionally, transcranial approaches to such lesions include the cranio-orbitozygomatic approach, anterior and posterior transpetrosal approach, and retrosigmoid approach., $, 23,31,39,40,44$ In recent years, the evolution of neuroendoscopic techniques has markedly improved the instrumentation and neurosurgi-

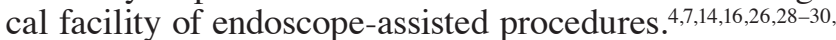
33,35,36 An endoscopic endonasal approach has emerged as an alternative to the classic surgical approaches, providing a direct route to the anteromedial region of Meckel's cave. ${ }^{1,2,6,8,22,24,31,32,34-36,44,45}$ However, such an approach still has a limited role for skull base lesions involving Meckel's cave and the middle cranial fossa, because it requires destruction of the normal nasal cavity, relatively long working distance, a potential risk of CSF leak, and injury of the vidian nerve, often leading to dry eye. In contrast, eTOA provides direct access and a short working distance to off-midline skull base lesions. Thus, the feasibility of eTOA has been vigorously investigated in several cadaveric studies.
Since Moe et al. first introduced a series of 16 patients treated with pure eTOA to anterior skull base pathology, including repair of CSF leak, optic nerve decompression, repair of basal skull fractures, and removal of skull base tumors, ${ }^{28}$ a variety of skull base pathologies have been added to the applications of eTOA..$^{8,9,18,35,38}$ eTOA has several advantages over open transcranial approaches for skull base tumors involving Meckel's cave and the middle cranial fossa. First, it minimizes the size of the craniectomy, which is limited to the greater wing of the sphenoid bone. Such less-invasive bone exposure markedly diminishes the risk of cosmetic and functional sequelae. Furthermore, this approach does not injure the temporalis muscle, resulting in no risk of temporalis atrophy. ${ }^{3,8} \mathrm{Sec}-$ ond, as with an endoscopic endonasal procedure, eTOA obviates the need for temporal lobe retraction and avoids the potential risk of injury to the vein of Labbé, thus decreasing the risk of postoperative brain swelling. This, in turn, contributes to rapid postoperative recovery and reduces the length of hospital stay. ${ }^{20,22,40}$

With regard to the details of the surgical technique involving eTOA, there are some anatomical landmarks that 

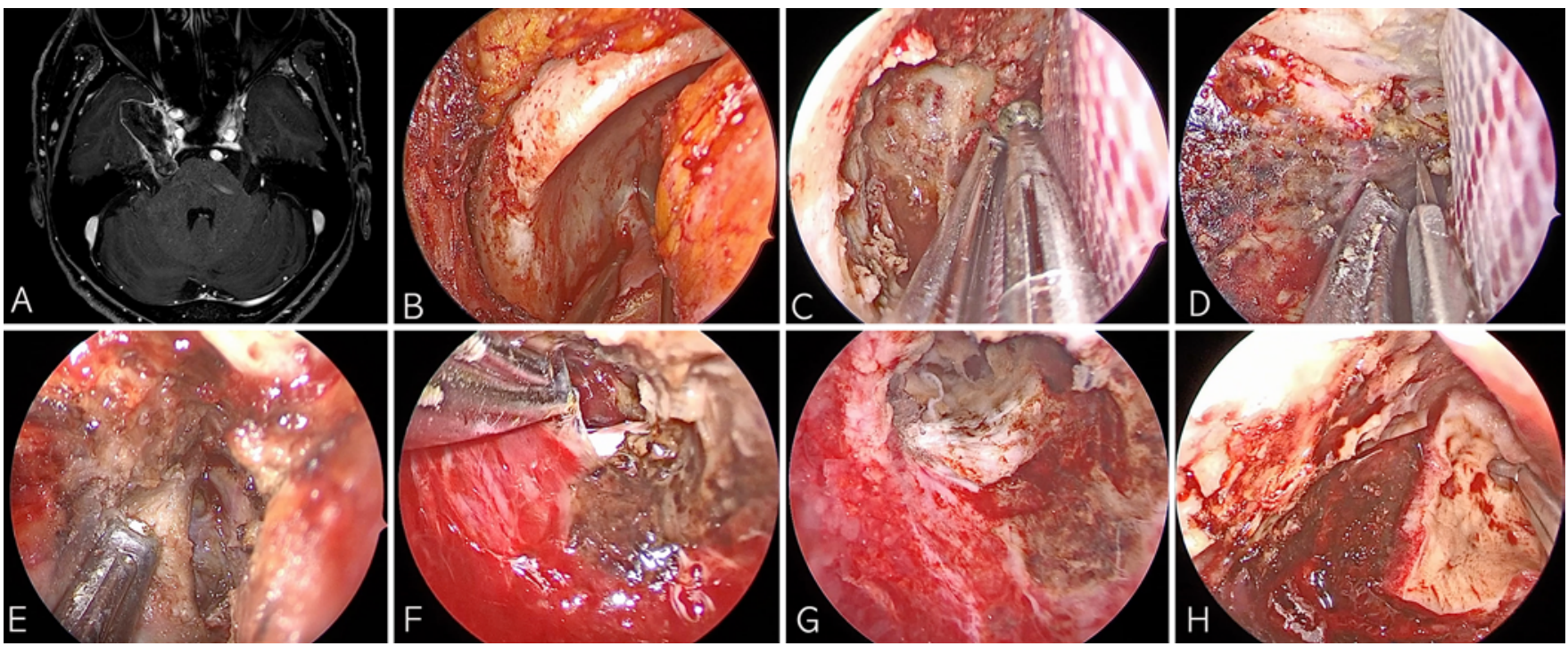

FIG. 3. Illustrative case 4. A 64-year-old woman with a trigeminal schwannoma involving the middle cranial fossa (A). During the endoscopic transorbital superior eyelid approach, subperiosteal elevation was performed along the lateral orbital wall (B). Bony drilling was started from the lateral to the medial side of the greater sphenoid wing (C). The MOB was exposed and cut (D). Profuse bleeding from the cavernous sinus was encountered, but was easily controlled with a Floseal. The tumor was exposed between the outer cavernous membrane and the dural propria (E). After removal of the tumor within Meckel's cave, some portion of the tumor extending into the posterior fossa was found $(\mathbf{F})$. Gross-total resection was done (G). Allograft dermis was placed for the dural defect $(\mathbf{H})$ and polymerized absorbable Medpor was used for reconstruction.
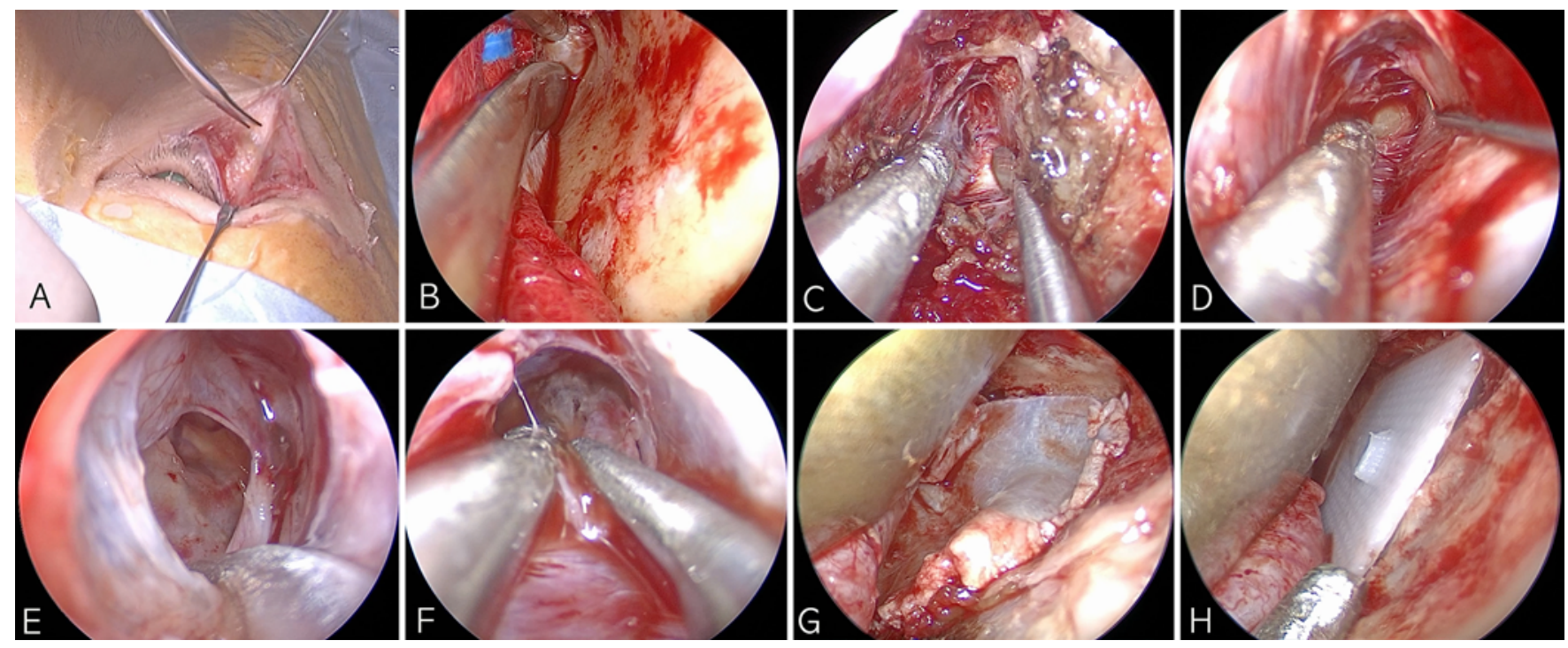

FIG. 4. Illustrative case 6. A 60-year-old woman presented with sudden dizziness from the rupture of a dermoid cyst. MR imaging showed a high signal intensity lesion within Meckel's cave. An endoscopic transorbital superior eyelid crease approach was performed. Subocularis dissection was carefully performed so as not to injure the levator aponeurosis (A). Gentle subperiosteal elevation along the lateral orbital wall exposed the superior orbital fissure (B). After identification of the MOB, dissection of the MOB exposed the interdural plane (C). The dermoid capsule within Meckel's cave was exposed (D). After dermoid contents were removed, Meckel's cave and the posterior fossa space were identified (E). The dermoid capsule was removed (F). Allograft fascia lata was placed for reconstruction of the dural defect $(\mathbf{G})$. Finally, polymerized absorbable Medpor was placed to prevent postoperative enophthalmos $(\mathbf{H})$.

should be taken into account. During the periosteal elevation along the lateral wall of the orbit, the SOF is the first landmark to identify before drilling the greater sphenoid wing and orbital roof. When dealing with exposing the margin of the IOF, it is essential to keep the subperiosteal dissection toward the inferomedial side. The greater sphenoid wing has a wide triangular shape. Drilling of the lateral orbital wall in the same direction also provides 

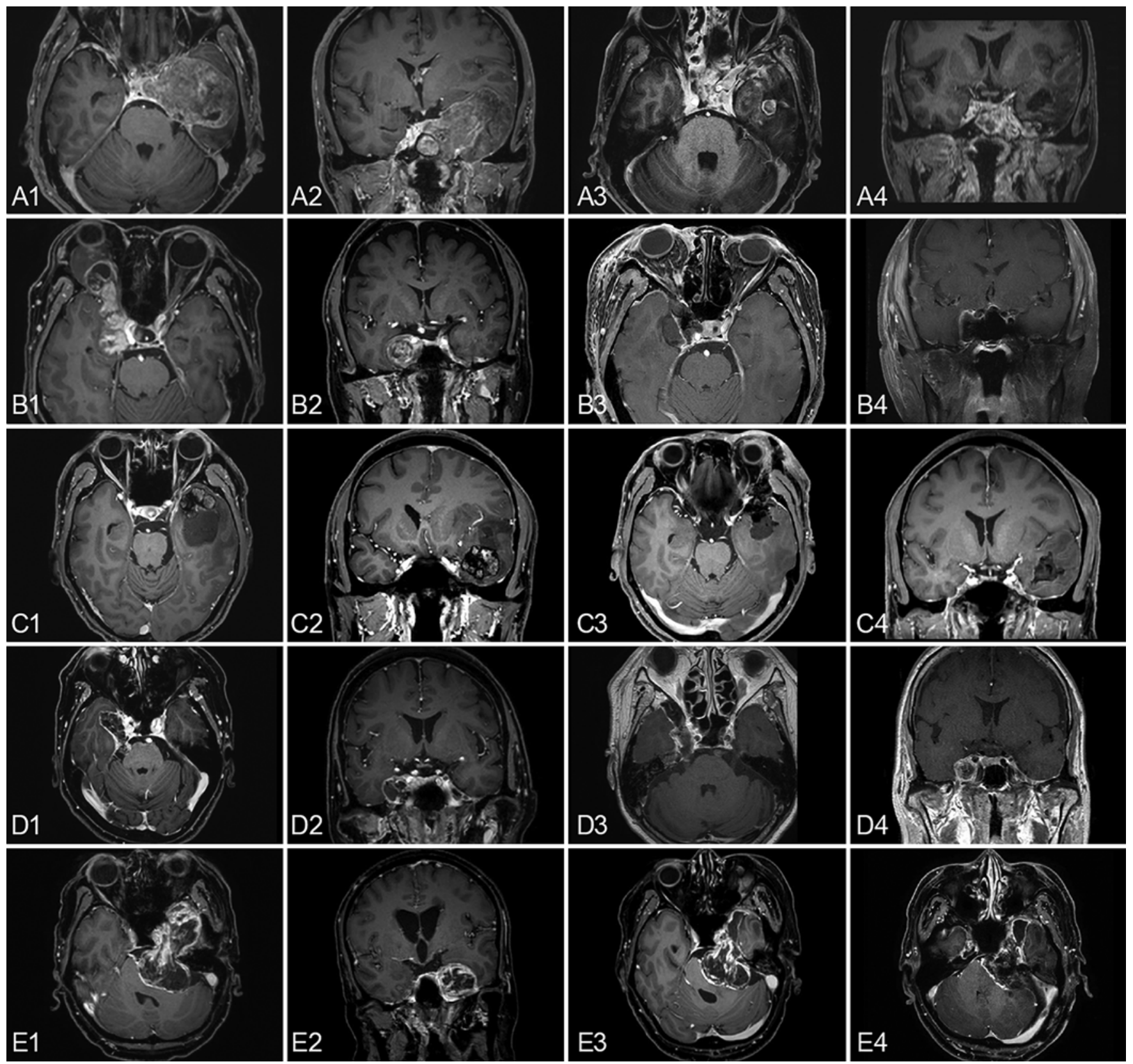

FIG. 5. Preoperative and postoperative MR images obtained in this series for cases 1-5. A: Case 1, chondrosarcoma involving Meckel's cave, the middle cranial fossa, and the infratemporal fossa shown on the preoperative MR images (A1 and A2) and postoperative MR images (A3 and A4) after GTR. B: Case 2, trigeminal schwannoma involving the orbit and Meckel's cave on preoperative MR images (B1 and B2) and postoperative MR images (B3 and B4) after GTR. C: Case 3, metastatic brain tumor on the preoperative MR images (C1 and C2) and postoperative MR images (C3 and C4) after GTR. D: Case 4, trigeminal schwannoma involving the middle cranial fossa on the preoperative MR images (D1 and D2) and postoperative MR images (D3 and D4) after GTR. E: Case 5, trigeminal schwannoma on the preoperative MR images (E1 and E2) and postoperative MR images after an intended PTR using eTOA (E3), followed by the retrosigmoid approach for the remaining posterior fossa tumor (E4).

sufficient working space. Next, the MOB tethering the frontotemporal basal dura to the periorbita is the second landmark to expose, and then the interdural space in the lateral wall of the cavernous sinus is employed to reach Meckel's cave without interrupting the venous compartment (Fig. 1). The MOB is not a true anatomical structure but a periosteal band stretching between the periorbita and the temporal lobe dura. ${ }^{11,18}$ Sharp dissection of this fibrotic band exposes the interdural plane composed of the space between the outer membrane of the cavernous sinus and the dura propria. This avascular dissection plane introduces the route to Meckel's cave and, most importantly, avoids profuse bleeding from the cavernous sinus. In such a way, this approach can minimize the retraction 

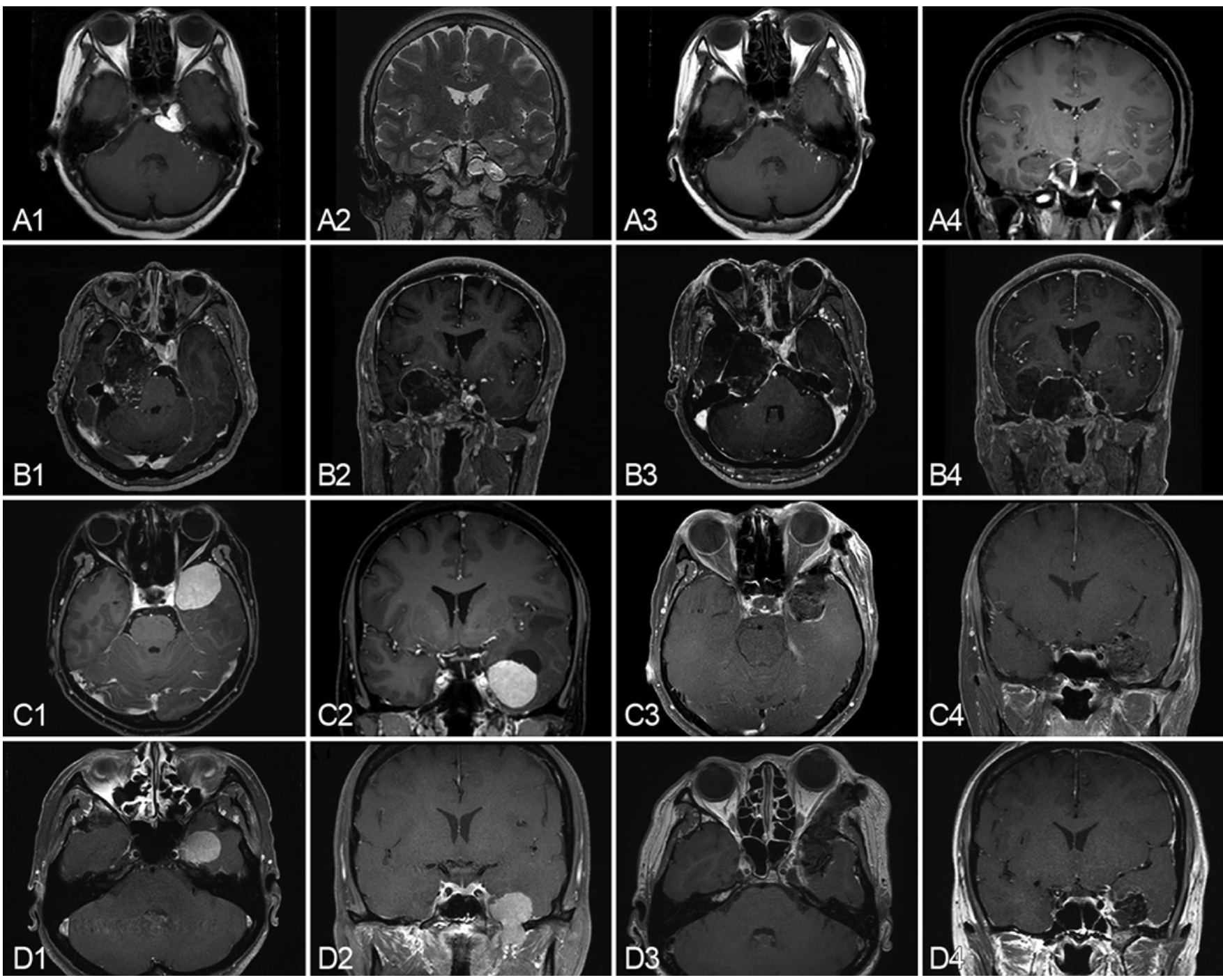

FIG. 6. Preoperative and postoperative MR images obtained in this series for cases 6-9. A: Case 6, dermoid cyst rupture on the preoperative MR images (A1 and A2) and postoperative MR images (A3 and A4) after GTR. B: Case 7, trigeminal schwannoma preoperative MR images (B1 and B2) and postoperative MR images (B3 and B4) after GTR. C: Case 8, middle cranial fossa meningioma on the preoperative MR images (C1 and C2) and postoperative MR images (C3 and C4). D: Case 9, middle cranial fossa meningioma on the preoperative MR images (D1 and D2) and postoperative MR images (D3 and D4).

of the temporal lobe. In our preliminary experience, the anteromedial triangle, which is composed of the space between the ophthalmic branch (V1) and maxillary branch of the trigeminal nerve (V2), is the major entrance route to Meckel's cave. Exposure to this space through interdural dissection is mandatory for removal of tumors involving Meckel's cave. As an additional limiting factor, there is the crowding of endoscopic instruments within the posterior fossa. Indeed, a more extensive exposure to the lateral part of the V2 nerve (anterolateral triangle) may be required to remove tumors extending to the posterior fossa, such as dumbbell-shaped tumors. For a large-sized, intradural lesion within the middle cranial fossa, as illustrated in our series, a simple dural opening reveals the whole anterior pole of the temporal lobe and provides access to the lesion without retraction of the lateral temporal lobe. If necessary, the lateral orbital rim can be removed with chiseling, allowing use of the instruments more freely (so-called extended eTOA).

This preliminary study shows the feasibility of eTOA for tumors involving the middle cranial fossa and Meckel's cave. However, the present study has the limitation that the small sample size is insufficient to prove the usefulness of this novel approach and to propose surgical indications. In addition, a longer follow-up is required to clearly elucidate the clinical efficacy as an alternative to conventional transcranial approaches. Last, as with any novel surgical procedure, there is a steep learning curve with the eTOA surgery. A thorough understanding of the anatomy of the orbit and cavernous sinus is essential to achieve satisfactory clinical outcomes in the treatment of skull base lesions involving Meckel's cave and the middle cranial fossa. Despite several limitations, this study, to our knowledge, is the first description of a clinical series in which all patients 
were treated with the approach of endoscopic minimally invasive access to middle fossa tumors using transorbital routes via the superior eyelid. In this study, GTR was achieved with few morbidities and no mortality.

\section{Conclusions}

In conclusion, our results demonstrate the feasibility of a novel endoscopic minimally invasive transorbital approach to remove deep-seated skull base tumors. This approach can be considered a feasible alternative treatment modality in the modern neurosurgical armamentarium for Meckel's cave tumors. Further accumulation of experience and extensive cadaveric studies are required in the future.

\section{Acknowledgments}

This study was supported by the Ministry of Health \& Welfare, Republic of Korea; the National Research Foundation of Korea; the Ministry of Science, ICT and Future Planning (MSIP) of Korea; grants (NRF-2015M3A9A7029740, NRF2015M3C9A1044522, and NRF-2015M3A9B5053642) from the National Research Foundation funded by the MSIP of Korea; and by a grant from Samsung Medical Center.

\section{References}

1. Al-Mefty O, Ayoubi S, Gaber E: Trigeminal schwannomas: removal of dumbbell-shaped tumors through the expanded Meckel cave and outcomes of cranial nerve function. J Neurosurg 96:453-463, 2002

2. Al-Mefty O, Fox JL, Smith RR: Petrosal approach for petroclival meningiomas. Neurosurgery 22:510-517, 1988

3. Almeida JP, Omay SB, Shetty SR, Chen YN, Ruiz-Treviño AS, Liang B, et al: Transorbital endoscopic eyelid approach for resection of sphenoorbital meningiomas with predominant hyperostosis: report of 2 cases. J Neurosurg 128:18851895, 2018

4. Almeida JP, Ruiz-Treviño AS, Shetty SR, Omay SB, Anand VK, Schwartz TH: Transorbital endoscopic approach for exposure of the sylvian fissure, middle cerebral artery and crural cistern: an anatomical study. Acta Neurochir (Wien) 159:1893-1907, 2017

5. Alqahtani A, Padoan G, Segnini G, Lepera D, Fortunato S, Dallan I, et al: Transorbital transnasal endoscopic combined approach to the anterior and middle skull base: a laboratory investigation. Acta Otorhinolaryngol Ital 35:173-179, 2015

6. Bly RA, Ramakrishna R, Ferreira M, Moe KS: Lateral transorbital neuroendoscopic approach to the lateral cavernous sinus. J Neurol Surg B Skull Base 75:11-17, 2014

7. Burkhardt JK, Holzmann D, Strobl L, Woernle CM, Bosch MM, Kollias SS, et al: Interdisciplinary endoscopic assisted surgery of a patient with a complete transorbital intracranial impalement through the dominant hemisphere. Childs Nerv Syst 28:951-954, 2012

8. Chen HI, Bohman LE, Loevner LA, Lucas TH: Transorbital endoscopic amygdalohippocampectomy: a feasibility investigation. J Neurosurg 120:1428-1436, 2014

9. Dallan I, Castelnuovo P, Locatelli D, Turri-Zanoni M, AlQahtani A, Battaglia P, et al: Multiportal combined transorbital transnasal endoscopic approach for the management of selected skull base lesions: preliminary experience. World Neurosurg 84:97-107, 2015

10. Dallan I, Castelnuovo P, Turri-Zanoni M, Fiacchini G, Locatelli D, Battaglia P, et al: Transorbital endoscopic assisted management of intraorbital lesions: lessons learned from our first 9 cases. Rhinology 54:247-253, 2016
11. Dallan I, Di Somma A, Prats-Galino A, Solari D, Alobid I, Turri-Zanoni M, et al: Endoscopic transorbital route to the cavernous sinus through the meningo-orbital band: a descriptive anatomical study. J Neurosurg 127:622-629, 2017

12. Dallan I, Locatelli D, Turri-Zanoni M, Battaglia P, Lepera D, Galante N, et al: Transorbital endoscopic assisted resection of a superior orbital fissure cavernous haemangioma: a technical case report. Eur Arch Otorhinolaryngol 272:3851-3856, 2015

13. Dallan I, Sellari-Franceschini S, Turri-Zanoni M, de Notaris M, Fiacchini G, Fiorini FR, et al: Endoscopic transorbital superior eyelid approach for the management of selected spheno-orbital meningiomas: preliminary experience. Oper Neurosurg (Hagerstown) 14:243-251, 2018

14. Di Somma A, Andaluz N, Cavallo LM, de Notaris M, Dallan I, Solari D, et al: Endoscopic transorbital superior eyelid approach: anatomical study from a neurosurgical perspective. J Neurosurg 129:1203-1216, 2018

15. Di Somma A, Andaluz N, Cavallo LM, Topczewski TE, Frio F, Gerardi RM, et al: Endoscopic transorbital route to the petrous apex: a feasibility anatomic study. Acta Neurochir (Wien) 160:707-720, 2018

16. Essayed WI, Singh H, Lapadula G, Almodovar-Mercado GJ, Anand VK, Schwartz TH: Endoscopic endonasal approach to the ventral brainstem: anatomical feasibility and surgical limitations. J Neurosurg 127:1139-1146, 2017

17. Ferrari M, Schreiber A, Mattavelli D, Belotti F, Rampinelli V, Lancini D, et al: The inferolateral transorbital endoscopic approach: a preclinical anatomic study. World Neurosurg 90:403-413, 2016

18. Fukuda H, Evins AI, Burrell JC, Iwasaki K, Stieg PE, Bernardo A: The meningo-orbital band: microsurgical anatomy and surgical detachment of the membranous structures through a frontotemporal craniotomy with removal of the anterior clinoid process. J Neurol Surg B Skull Base 75:125-132, 2014

19. Hardesty DA, Prevedello DM: What are the limits of endoscopic endonasal approaches to the skull base? J Neurosurg Sci 62:285-286, 2018

20. Inoue T, Rhoton AL Jr, Theele D, Barry ME: Surgical approaches to the cavernous sinus: a microsurgical study. Neurosurgery 26:903-932, 1990

21. Jouanneau E, Simon E, Jacquesson T, Sindou M, Tringali S, Messerer M, et al: The endoscopic endonasal approach to the Meckel's cave tumors: surgical technique and indications. World Neurosurg 82 (6 Suppl):S155-S161, 2014

22. Kassam AB, Prevedello DM, Carrau RL, Snyderman CH, Gardner P, Osawa S, et al: The front door to Meckel's cave: an anteromedial corridor via expanded endoscopic endonasal approach-technical considerations and clinical series. Neurosurgery 64 (3 Suppl):ons71-ons83, 2009

23. Kawase T, Shiobara R, Toya S: Anterior transpetrosaltranstentorial approach for sphenopetroclival meningiomas: surgical method and results in 10 patients. Neurosurgery 28:869-876, 1991

24. Komatsu F, Komatsu M, Di Ieva A, Tschabitscher M: Endoscopic approaches to the trigeminal nerve and clinical consideration for trigeminal schwannomas: a cadaveric study. J Neurosurg 117:690-696, 2012

25. Koutourousiou M, Gardner PA, Stefko ST, Paluzzi A, Fernandez-Miranda JC, Snyderman CH, et al: Combined endoscopic endonasal transorbital approach with transconjunctival-medial orbitotomy for excisional biopsy of the optic nerve: technical note. J Neurol Surg Rep 73:52-56, 2012

26. Locatelli D, Pozzi F, Turri-Zanoni M, Battaglia P, Santi L, Dallan I, et al: Transorbital endoscopic approaches to the skull base: current concepts and future perspectives. J Neurosurg Sci 60:514-525, 2016

27. Luginbuhl AJ, Campbell PG, Evans J, Rosen M: Endoscopic 
repair of high-flow cranial base defects using a bilayer button. Laryngoscope 120:876-880, 2010

28. Moe KS, Bergeron CM, Ellenbogen RG: Transorbital neuroendoscopic surgery. Neurosurgery 67 (3 Suppl Operative):ons16-ons28, 2010

29. Moe KS, Kim LJ, Bergeron CM: Transorbital endoscopic repair of cerebrospinal fluid leaks. Laryngoscope 121:13-30, 2011

30. Moussazadeh N, Prabhu V, Bander ED, Cusic RC, Tsiouris AJ, Anand VK, et al: Endoscopic endonasal versus open transcranial resection of craniopharyngiomas: a case-matched single-institution analysis. Neurosurg Focus 41(6):E7, 2016

31. Muto J, Kawase T, Yoshida K: Meckel's cave tumors: relation to the meninges and minimally invasive approaches for surgery: anatomic and clinical studies. Neurosurgery 67 (3 Suppl Operative):ons291-ons298, 2010

32. Niranjan A, Barnett S, Anand V, Agazzi S: Multimodality management of trigeminal schwannomas. J Neurol Surg B Skull Base 77:371-378, 2016

33. Ottenhausen M, Rumalla K, Alalade AF, Nair P, La Corte E, Younus I, et al: Decision-making algorithm for minimally invasive approaches to anterior skull base meningiomas. Neurosurg Focus 44(4):E7, 2018

34. Priddy BH, Nunes CF, Beer-Furlan A, Carrau R, Dallan I, Prevedello DM: A side door to Meckel's cave: anatomic feasibility study for the lateral transorbital approach. Oper Neurosurg (Hagerstown) 13:614-621, 2017

35. Ramakrishna R, Kim LJ, Bly RA, Moe K, Ferreira M Jr: Transorbital neuroendoscopic surgery for the treatment of skull base lesions. J Clin Neurosci 24:99-104, 2016

36. Raza SM, Amine MA, Anand V, Schwartz TH: Endoscopic endonasal resection of trigeminal schwannomas. Neurosurg Clin N Am 26:473-479, 2015

37. Raza SM, Donaldson AM, Mehta A, Tsiouris AJ, Anand VK, Schwartz TH: Surgical management of trigeminal schwannomas: defining the role for endoscopic endonasal approaches. Neurosurg Focus 37(4):E17, 2014

38. Rivkin MA, Turtz AR, Morgenstern KE: Transorbital endoscopic removal of posterior lateral orbital mass. Laryngoscope 123:3001-3004, 2013

39. Samii M, Migliori MM, Tatagiba M, Babu R: Surgical treatment of trigeminal schwannomas. J Neurosurg 82:711-718, 1995

40. Sanna M, Bacciu A, Pasanisi E, Taibah A, Piazza P: Posterior petrous face meningiomas: an algorithm for surgical management. Otol Neurotol 28:942-950, 2007

41. Schaberg M, Murchison AP, Rosen MR, Evans JJ, Bilyk JR: Transorbital and transnasal endoscopic repair of a meningoencephalocele. Orbit 30:221-225, 2011
42. Shin M, Kondo K, Saito N: Neuroendoscopic transnasal surgery for skull base tumors: basic approaches, avoidance of pitfalls, and recent innovations. Neurol Med Chir (Tokyo) 52:697-703, 2012

43. Sonig A, Nanda A: Transorbital approach to the anterior cranial skull base. World Neurosurg 80:810-812, 2013

44. Sun DQ, Menezes AH, Howard MA III, Gantz BJ, Hasan DM, Hansen MR: Surgical management of tumors involving Meckel's cave and cavernous sinus: role of an extended middle fossa and lateral sphenoidectomy approach. Otol Neurotol 39:82-91, 2018

45. Truong HQ, Sun X, Celtikci E, Borghei-Razavi H, Wang EW, Snyderman $\mathrm{CH}$, et al: Endoscopic anterior transmaxillary "transalisphenoid" approach to Meckel's cave and the middle cranial fossa: an anatomical study and clinical application. J Neurosurg [epub ahead of print February 2, 2018; DOI: 10.3171/2017.8.JNS171308]

\section{Disclosures}

The authors report no conflict of interest concerning the materials or methods used in this study or the findings specified in this paper.

\section{Author Contributions}

Conception and design: Kong. Acquisition of data: Kong, Choi. Analysis and interpretation of data: Kong. Drafting the article: Jeon, CK Hong. Critically revising the article: CK Hong, Lee. Reviewed submitted version of manuscript: Jeon, Nam. Statistical analysis: Woo. Administrative/technical/material support: SD Hong, Lee. Study supervision: SD Hong, Nam, Seol.

\section{Supplemental Information \\ Videos}

Video 1. https://vimeo.com/285102743.

Video 2. https://vimeo.com/285102757.

\section{Correspondence}

Doo-Sik Kong: Samsung Medical Center, Sungkyunkwan University School of Medicine, Seoul, Republic of Korea.neurokong@ gmail.com; kds026@skku.edu. 